\section{Inpatient care cost of schizophrenia in Ireland: underestimation due to non-inclusion on data on new long-stay patients}

Dear Editor, Re the letter in the September 2009 edition of $/ r$ J psych Med (2009; 26(3): 151-154), by Behan et al.

Many thanks to Behan et al for clarifying their methodology. They agree that the $€ 32.1$ million figure they arrived is still an underestimate. This figure is based on the data reported by the Health Research Board, Dublin. ${ }^{1}$

I wish to add to this figure in view of the new audit information on new long stay patients, reported by Daly and Walsh, of the Health Research Board (HRB) team, published in the same edition of the Irish Journal of Psychological Medicine. ${ }^{2}$

Annual reports published by the HRB, have consistently not considered the length of stay and bed-days data on the patients staying in the psychiatric units over one year. ${ }^{1}$

The audit of new long-stay patients, patients staying between one to five years in inpatient psychiatric services, has identified 548 in the national census on March 31, 2006. After exclusions, such as for the patients residing in private psychiatric hospitals, data on 460 patients was available for the calculation of the length of stay (LOS). Of those patients $42 \%(192 / 460)$ of patients had a diagnosis of schizophrenia.

The median length of stay in these patients was approximately 33 months ( 1,000 days). If averaged out for five years it comes to approximately 200 days. For simplicity of calculations we will consider the average cost of a bed as $€ 250$ per day. This is the figure considered by Behan et al, for bed cost per day for a patient admitted in a psychiatric unit attached to a general hospital; as according to HRB annual report of 2006 nearly $53 \%$ of psychiatric admissions are to the psychiatric units based in a general hospital.,2,3

The average cost of these new long-stay patients with schizophrenia, will be approximately $€ 10$ million $(192 \times 200$ $\times 250$ ). Thus the 'at least' cost of inpatient care for schizophrenia in Ireland would be approximately $€ 42$ million. As suggested by Behan et al, this is still an underestimate as the data reported by the Health Research Board of new longstay patients still excludes patients $(n=67)$ residing in private psychiatric hospitals. $^{2}$

\section{Ajay Dixit, Registrar, General Adult Psychiatry, Mercy University Hospital, Cork, Ireland. Email: drajaydixit@yahoo.com} 2006. Health Research Board Annual reports, Dublin 2006. (Table 2.12: pg 50). 2. Daly A, Walsh D. An audit of new long-stay patients in Irish psychiatric in-patient services. Ir J Psych Med 2009; 26(3):134-139.

3. Behan C, Kennelly B, O'Callaghan E.The economic cost of schizophrenia in Ireland: a cost of illness study. Ir J psych Med (2009; 26(3): 151-154

\section{Response to Dr Dixit regarding the economic cost of schizophrenia in Ireland}

Dear Editor, We thank Dr Dixit for his ongoing interest in our study and in the economic cost of schizophrenia in Ireland. ${ }^{1}$ While we concur with Dr Dixit's overall view, we need to clarify some of the figures he attributes to our paper. ${ }^{2}$ The $€ 32.1$ million Dr Dixit quotes in his letter was actually our estimate of just the inpatient costs alone, we estimate the overall cost of schizophrenia to Ireland was $€ 460.1$ million in 2006. In his calculations Dr Dixit quotes our inpatient cost as $€ 250$ in 2006. In fact, the cost of an inpatient unit in a general hospital we used, was €247. The cost of a bed day in a psychiatric hospital was $€ 313$. Using an average of the two, this is a cost per bed day of $€ 280$. Private hospital costs were even more expensive. Nevertheless, Dr Dixit's further work on this theme emphasises how important this matter is and further emphasises our conservative estimate.

Costs of illness studies are useful in providing an estimate of the costs of an illness to the patient, their family and to society. However, by their nature they have their limitations, including the omission of intangible costs, often the most important cost to the patient and their families. Intangible costs include the cost of suffering and quality of life. It is unfortunate, even aside from human suffering and lost human potential, that obvious measures to reduce costs, such as introduction of early intervention services to reduce the duration of untreated psychosis, have not been adopted in Ireland as they have in other countries around the globe to such good effect.

Recent studies in the UK, Scandinavia, Canada and Australia comparing early intervention services with treatment as usual show reduced costs in the short-term, mainly due to a reduction in inpatient costs. ${ }^{3-6} \mathrm{~A}$ recent study from EPPIC in Australia showed that costs, and benefits such as increase in remission and greater numbers in paid employment, persist over the longer-term. ${ }^{7}$

The recovery model of treating mental health disorders, in line with prevention models such as screening in the treatment of physical health disorders, would suggest that recovery from an illness is faster, more effective and potentially cheaper if an illness is caught early when the individual is often less unwell. This makes sense in any climate, let alone our current one. Introduction of early intervention services in Ireland, as proposed in Vision for Change, can best be done by joint initiatives from primary care and secondary care.

Caragh Behan, Senior Registrar, General Adult Psychiatry, Cluain Mhuire Family Services, Newtown Park Avenue, Blackrock, Co Dublin, Ireland.

Brendan Kennelly, Department of Economics, National University of Ireland, Galway, Ireland.

Eadbhard O'Callaghan,

DETECT, Early Intervention for Psychosis, Dublin and Dept of Psychiatry, School of Medicine, University College Dublin, Belfield, Dublin 4, Ireland. 